\title{
Genetic and maternal effect influences on viability of common frog tadpoles under different environmental conditions
}

\author{
S Pakkasmaa ${ }^{1}$, J Merilä ${ }^{2}$ and RB O'Hara ${ }^{2,3}$ \\ ${ }^{1}$ Department of Population Biology, Evolutionary Biology Centre, Uppsala University, Norbyvägen 18D, SE-75236 Uppsala, Sweden; \\ ${ }^{2}$ Ecological Genetics Research Unit, Department of Ecology and Systematics, PO Box 65, FIN-00014 University of Helsinki, Finland; \\ ${ }^{3}$ Rolf Nevanlinna Institute, PO Box 4, FIN-00014 University of Helsinki, Finland
}

\begin{abstract}
The influence of environmental stress on the expression of genetic and maternal effects on the viability traits has seldom been assessed in wild vertebrates. We have estimated genetic and maternal effects on the viability (viz probability of survival, probability of being deformed, and body size and shape) of common frog, Rana temporaria, tadpoles under stressful (low $\mathrm{pH}$ ) and nonstressful (neutral $\mathrm{pH}$ ) environmental conditions. A Bayesian analysis using generalized linear mixed models was applied to data from a factorial laboratory experiment. The expression of additive genetic variance was independent of $\mathrm{pH}$ treatments, and all traits were significantly heritable (survival: $h^{2} \approx 0.08$; deformities: $h^{2} \approx 0.26$; body size: $h^{2} \approx 0.12$; body shape: $h^{2} \approx 0.14$ ). Likewise, nonadditive genetic contributions to variation in
\end{abstract}

all traits were significant, independent of $\mathrm{pH}$ treatments and typically of magnitude similar to the additive genetic effects. Maternal effects were large for all traits, especially for viability itself, and their expression was partly dependent on the environment. In the case of body size, the maternal effects were mediated largely through egg size. In general, the results give little evidence for the conjecture that environmental stress created by low $\mathrm{pH}$ would impact strongly on the genetic architecture of fitness-related traits in frogs, and hamper adaptation to stress caused by acidification. The low heritabilities and high dominance contributions conform to the pattern typical for traits subject to relatively strong directional selection.

Heredity (2003) 91, 117-124. doi:10.1038/sj.hdy.6800289

Keywords: Bayesian models; environmental stress; heritability; maternal effects; $\mathrm{pH}$; Rana temporaria

\section{Introduction}

Environmental changes caused by anthropogenic activities have exposed many wild plant and animal populations to increasing levels of environmental stress, and concern about the ability of organisms to adapt to these changes has grown steadily (eg, Bijlsma and Loeschcke, 1997; Hoffmann and Parsons, 1997; Forbes, 1999; Walther et al, 2002). Although quantitative genetic studies have revealed that most traits and populations harbor large amounts of additive genetic variation (eg, Mousseau and Roff, 1987; Houle, 1992), two issues of concern have emerged. First, the magnitude of environmental changes may be so large and/or the changes so rapid that genetic variability can become exhausted before adaptation is complete (Lynch and Lande, 1993; Bürger and Lynch, 1997). Second, environmental stress can reduce the expression of additive genetic variance and increase the environmental component of variance in a given trait, thereby constraining the process of adaptation in populations living under environmental stress (Hoffmann and Merilä, 1999). Hence, to make predictions about selection responses and the likelihood of genetic

Correspondence: J Merilä, Ecological Genetics Research Unit, Department of Ecology and Systematics, PO Box 65, FIN-00014 University of Helsinki, Finland. E-mail: juha.merila@helsinki.fi

Received 29 July 2002; accepted 11 February 2003 adaptation under stressful conditions, we need to understand not only the properties and dynamics of the fitness landscape (cf, Arnold et al, 2001), but also how the expression of genetic variation is modified by ecologically relevant stress situations.

Experimental work on the effects of environmental stress on heritability and the expression of additive genetic variation in metric traits is inconclusive (Hoffmann and Merilä, 1999; Hoffmann and Hercus, 2000). Both decreased and increased heritabilities under stressful environmental conditions have been observed, and the underlying causes have been attributed to changes in both the additive and the environmental components of variance (Hoffmann and Merilä, 1999). One complicating factor hampering generalizations about the effects of environmental stress on the quantitative genetic parameters is the heterogeneous methodologies employed by different studies. Many studies have utilized methods incapable of distinguishing additive genetic from nonadditive and maternal effect contributions, and consequently, the observed changes in heritability estimates cannot be unambiguously attributed to changes in any particular component of the phenotypic variance (Hoffmann and Merilä, 1999). For instance, two recent Drosophila studies (Bubliy et al, 2000, 2001) using methods capable of estimating pure $V_{\mathrm{A}}$ failed to confirm any environment dependency in the levels of $V_{\mathrm{A}}$ reported by some earlier studies (eg, Sgró and Hoffmann, 
1998), suggesting a role for nonadditive genetic effects in biasing the earlier results. Likewise, although parentoffspring regression estimates of heritability are in principle free from bias because of dominance effects, this method may also give biased estimates of heritability and $V_{\mathrm{A}}$ when the parents and offspring have been grown in different environments (Riska et al, 1989; Merilä, 1997; Merilä and Fry, 1998). Hence, excluding studies using methods open to alternative interpretations, the data available on the effects of environmental stress on quantitative genetic parameters are both numerically and taxonomically limited.

No amphibian studies on the effects of environmental stress on quantitative genetic parameters have yet been published, although the early aquatic developmental stages of amphibians are known to be extremely sensitive to various environmental stresses, such as ultraviolet-B radiation (Blaustein et al, 1998), chemical pollutants (Hecnar, 1995; Rosenshield et al, 1999; Bridges and Semlitsch, 2000) and acidification (Böhmer and Rahman, 1990). In fact, the recent global decline of amphibian populations (Alford and Richards, 1999; Houlahan et al, 2000) is believed to be - at least in part - a reflection of worldwide increase in the levels of these stresses (Alford and Richards, 1999; Corn, 2000). To this end, studies on the genetic basis of amphibian stress responses can be useful in elucidating the likelihood of adaptation to increasing levels of environmental stress, as well as in addressing the general question about the possible difference in evolutionary potential under stressful and nonstressful environmental conditions (Hoffmann and Merilä, 1999). An additional reason why amphibians are interesting in this context is that the literature suggests a pervasive role for maternal effects as determinants of amphibian fitness (review in Kaplan, 1998). Given that maternal effects have recently been advocated as a possible pathway for adaptation in a wide number of taxa (Mousseau and Fox, 1998), attempts to understand their potential role in adaptation to environmental stress could be rewarding. In fact, a number of studies have unravelled interactions between maternal effects and environmental conditions (Groeters and Dingle, 1987; Parichy and Kaplan, 1992; Einum and Fleming, 1999), suggesting that differential expression of maternal effects could be an important source of fitness variation under some, but not all, environmental conditions.

The aim of this study was to investigate the relative importance of genetic and maternal effects as determinants of phenotypic variation in viability and viabilityrelated traits in the common frog Rana temporaria. In particular, our interest was to assess whether the expression of additive genetic and maternal variances would differ between stressful (low $\mathrm{pH}$ ) and nonstressful (neutral $\mathrm{pH}$ ) environmental conditions. In addition, as egg size has been recognized as an important determinant of hatchling performance in amphibians (Kaplan, 1998) and vertebrates in general (reviews in Mousseau and Fox, 1998), we investigated whether the maternal effects could be accounted for by egg size effects alone, or whether they are attributable to factors uncorrelated with egg size (eg, maternal provision of nutrients and/or hormones). To avoid the interpretational caveats characterizing many of the previous experiments on the effects of environmental stress on quantitative genetic parameters, we studied these questions in a factorial laboratory experiment using a half-sib crossing design allowing estimation of heritabilites and additive genetic variances free of bias introduced by dominance and maternal effects, and by subjecting the data to a Bayesian generalized mixed model analysis.

\section{Materials and methods}

\section{Study species and crosses}

The common frog is a medium-sized anuran which, in our study area in central Sweden, breeds in small ponds and shallow lakeshores shortly after snow melt, usually in mid-April. Although common frogs seem to avoid low $\mathrm{pH}$ habitats, they do occur in ponds subject to natural or anthropogenic acidification (eg, Aston et al, 1987; Räsänen et al, 2002), and populations in northern Scandinavia are subject to 'acid pulses' (Reader and Dempsey, 1989; AMAP, 1998) caused by snow-melt water reaching their breeding ponds. Low $\mathrm{pH}$ is known to lead to reduced survival, increased frequency of developmental anomalies, delayed development and decreased growth rate in common frog tadpoles (eg Cummins, 1986; Andrén et al, 1988; Tyler-Jones et al, 1989; Räsänen et al, 2002).

Adult frogs forming the parental generation of this study were collected from two closely situated localities (to avoid creating too much disturbance in a single locality) near Uppsala, Central Sweden (Häggedalen, $59^{\circ} 51^{\prime} \mathrm{N}, 17^{\circ} 14^{\prime} \mathrm{E}$ and Gullsmyra, $\left.60^{\circ} 70^{\prime} \mathrm{N}, 16^{\circ} 56^{\prime} \mathrm{E}\right) 17-$ 19 April 2000. They were maintained in $+4^{\circ} \mathrm{C}$ (ca. 5 days) until crossed artificially (see below) in the laboratory according to a North Carolina I (NC I) design (Kearsey and Pooni, 1996). In brief, we created paternal half-sib families by crossing 30 males each with two different females, producing altogether 60 families. From each male, a sperm suspension was prepared on a Petri dish with $3 \mathrm{ml}$ of $10 \%$ Amphibian Ringer solution (Rugh, 1962). The eggs from two different females were stripped on two separate vials, ca. $1 \mathrm{ml}$ of the sperm suspension was added, and the fertilized eggs were gently shaken. After $5 \mathrm{~min}$, more Ringer solution was added to cover the eggs, and after $20 \mathrm{~min}$, the solution was replaced with reconstituted soft water (RSW; APHA, 1985). At $1 \mathrm{~h}$ after the fertilizations, a sample of about 30 eggs was photographed for later measurement of the average egg size of each female. Of the remaining eggs, about 250 eggs per cross (ca. 15000 eggs in total) were used in this experiment. The mean egg size differed significantly among females (ANOVA, $F_{57,1773}=68.76, P<0.001$ ), and the differences were related to differences in female body size: larger females tended to have larger eggs (ANCOVA, female identity: $F_{56,1773}=59.32, P<0.001$; female length: $\left.F_{1,1773}=30.22, P<0.001\right)$.

\section{Rearing of the eggs}

The eggs from each cross were divided into two $\mathrm{pH}$ treatments, five replicates per treatment, each replicate with approximately 25 eggs (mean $=24.4$ eggs; range $=15-51$ ), and reared in 0.91 opaque plastic vials in RSW. The $\mathrm{pH}$ treatments were selected based on earlier experience and information from the literature to represent stressful ( $\mathrm{pH}$ 4.6) and nonstressful ( $\mathrm{pH} 7.6)$ environmental conditions (Andrén et al, 1988; Räsänen et al, 2002). The water for the low $\mathrm{pH}$ treatment was 
prepared in 2001 tuns by adding $0.1-1 \mathrm{M} \mathrm{H}_{2} \mathrm{SO}_{4}$ (adjusting with $0.1-1 \mathrm{M} \mathrm{NaOH}$ ) to RSW and stabilized and aerated for at least $48 \mathrm{~h}$ before use. The water for the neutral $\mathrm{pH}$ treatment was prepared in the same way, but without adding any acid.

The vials were placed in a shelf-system divided into five horizontal blocks to control for the effect of varying temperature on embryonic development. Two vials per cross, one from each $\mathrm{pH}$ treatment, were placed in each block in a randomized order. Water in the vials was changed every third day to keep the rearing conditions constant. The temperature in the blocks varied slightly between the warmest (uppermost) block $\left(17.9^{\circ} \mathrm{C} \pm \mathrm{SD}\right.$ $0.35)$ and coldest (lowest) block $\left(17.1^{\circ} \mathrm{C} \pm S D\right.$ 0.34). Water $\mathrm{pH}$ was monitored daily from several vials with an Orion pH meter (model 250A) equipped with a Ross Sure-flow electrode (model $8172 \mathrm{BN}$ ). Slight variations in $\mathrm{pH}$ occurred during the course of the experiment, but this variation was small relative to the difference in treatment means.

The embryos were reared until the majority of the individuals in each vial had reached growth stage 25 (absorption of external gills and fully developed operculum; Gosner, 1960). For each replicate, we determined the proportion of surviving and anomalous (coiled or extremely shortened tail, asymmetric body, etc) tadpoles. Two normal individuals from each vial were randomly sampled and stored in $70 \%$ ethanol, and the experiment was terminated. Four morphological characters were measured on each sampled tadpole with a stereomicroscope fitted with an ocular micrometer. These were: body length (from the tip of the nose to the end of the body wall), maximum body depth, tail length (from the body terminus to the tip of the tail) and maximum tail depth. All measurements were made by the same person to avoid interobserver variation. To reduce variation in the morphological measurements into fewer uncorrelated variables, the measurements were subjected to a principal component analysis. The first component (PC1) accounted for $79.6 \%$ of the variation and was equally highly and postively loaded with all characters (factor loadings: 0.48-0.51), and thus can be interpreted as reflecting tadpole size. The second component (PC2) accounted for $9 \%$ of the total variation, and it reflected the contrast between tail length (loading: -0.86$)$ and the other characteristics (loadings: 0.21-0.42), and consequently was a shape component.

\section{Statistical analyses}

Number of survivors and anomalous individuals: The number of survivors and anomalous individuals were modelled using a generalized linear mixed model (Breslow and Clayton, 1993) and fitted with a Bayesian approach. The numbers of normal, abnormal and dead individuals were modelled as a nested response (McCullagh and Nelder, 1989). At the first level, individuals are either normal or not, and at the second level those that are not normal are either abnormal or dead. The number of normal tadpoles in batch $i, n_{i}$, was assumed to follow a binomial distribution, that is $n_{i} \sim \operatorname{Bin}\left(N_{i}, p_{i}\right)$, where $p_{i}$ is the probability of a single tadpole in batch $i$ being normal and $N_{i}$ is the total number of individuals. Similarly, if the number of abnormal (but live) tadpoles is $m_{i}$, then we assumed $m_{i} \sim \operatorname{Bin}\left(N_{i}-n_{i}, q_{i}\right)$, where $q_{i}$ is the probability of a single tadpole being abnormal, given that it is not classed as normal (the probability of it being abnormal is then $q_{i} /(1-$ $\left.p_{i}\right)$ ). We modelled $p_{i}$ and $q_{i}$ to study whether egg size and genetic and environmental effects on these probabilities would vary across environments. The structures of the two models are similar, and they are presented in terms of the numbers of normal tadpoles. The extension to the abnormal/dead category is obvious.

The dependence of $p_{i}$ on the factors is modelled as follows:

$$
\begin{aligned}
& \log \left(\frac{p_{i}}{1-p_{i}}\right)=\eta_{i}+\varepsilon_{i} \\
& \eta_{i}=\mu_{a}+\left(g_{i}-\bar{g}\right) \beta_{a}+\phi_{b}+\alpha_{f, a}
\end{aligned}
$$

where $\mu_{a}$ is the mean survival at $\mathrm{pH} a$ ( $a=1$ for high $\mathrm{pH}$, 2 for low $\mathrm{pH}), g_{i}$ is the mean size of eggs measured from the $i$ th female, $\bar{g}$ is the mean egg size and $\beta_{a}$ is the regression coefficient for the egg size at $\mathrm{pH} a . \phi_{b}$ is the effect of the $b$ th block. Both $\beta_{a}$ and $\phi_{b}$ are assumed to be constant across females. $\alpha_{f, a}$ is the mean effect of the $f$ th female at $\mathrm{pH} a$, and this contains the genetic variance and is modelled further (below). $\varepsilon_{i}$ captures any residual variance (ie environmental variation).

$\phi_{b}, \alpha_{f}$ and $\varepsilon_{i}$ are modelled as random effects as follows:

$$
\begin{aligned}
& \phi_{b} \sim N\left(0, v_{b}\right) \\
& \alpha_{f} \sim N\left(\varphi_{m}, v_{\mathrm{d}}\right) \\
& \varphi_{m} \sim N\left(0, v_{\mathrm{s}}\right) \\
& \varepsilon_{i} \sim N\left(0, v_{\mathrm{e}}\right)
\end{aligned}
$$

where $A \sim N(m, v)$ means that $A$ follows a normal distribution with mean $m$ and variance $v$. Here $\alpha_{f}$ is nested within $\varphi_{m}$. From this we obtain estimates of three 'statistical' variance components, the variance among sires $\left(v_{\mathrm{s}}\right)$, among dams within sires $\left(v_{\mathrm{d}}\right)$ and within full sib families $\left(v_{\mathrm{e}}\right)$, that can be related to the four 'biological' variance components (Lynch and Walsh, 1998) as:

$$
\begin{aligned}
& v_{\mathrm{S}}=\frac{1}{4} \sigma_{\mathrm{A}}^{2} \\
& v_{\mathrm{d}}=\frac{1}{4} \sigma_{\mathrm{A}}^{2}+\frac{1}{4} \sigma_{\mathrm{D}}^{2}+\sigma_{\mathrm{E}_{\mathrm{C}}}^{2} \\
& v_{\mathrm{e}}=\frac{1}{2} \sigma_{\mathrm{A}}^{2}+\frac{3}{4} \sigma_{\mathrm{D}}^{2}+\sigma_{\mathrm{E}_{\mathrm{S}}}^{2}
\end{aligned}
$$

where $\sigma_{\mathrm{A}}^{2}$ is the additive genetic variance, $\sigma_{\mathrm{D}}^{2}$ is the dominance genetic variance, $\sigma_{\mathrm{E}_{\mathrm{C}}}^{2}$ is the environmental variance because of a common environment (including maternal effects) and $\sigma_{\mathrm{E}_{\mathrm{S}}}^{2}$ is the environmental variance within a single family (here a single vial).

The model was fitted using a Bayesian approach (Gelman et al, 1995). This provides the advantage that we can estimate the full posterior distribution of the estimates of the biological variance components directly, whereas in a classical analysis the likelihood is maximized for $v_{\mathrm{S}}, v_{\mathrm{d}}$ and $v_{\mathrm{e}}$ and then $\sigma_{\mathrm{A}}^{2}, \sigma_{\mathrm{D}}^{2}, \sigma_{\mathrm{E}_{\mathrm{C}}}^{2}$ and $\sigma_{\mathrm{E}_{\mathrm{S}}}^{2}$ are calculated from the estimated values. It should be noted that the estimates of the genetic variance components are not independent but there are four unknown components being estimated from three statistical components. Taking a Bayesian approach allows us to estimate the components, but the estimates are correlated, and therefore the interpretation (especially of joint distributions) must be made with care. 
$\mu_{a}$ and $\beta_{a}$ were given normally distributed priors with mean 0 and variance of 1.5 and 1 , respectively (a variance of 1.5 was used for $\mu_{a}$ because it gives an almost flat prior on the probability scale). $\sigma_{\mathrm{A}}^{2}, \sigma_{\mathrm{D}}^{2}, \sigma_{\mathrm{E}_{\mathrm{C}}}^{2}$ and $\sigma_{\mathrm{E}_{\mathrm{S}}}^{2}$ were all given inverse gamma-distributed priors, with shape and scale parameters being equal to 1. Missing values (for instance, in cases when all sampled individuals were anomalous) were estimated using multiple imputation, which means that the missing observations were treated as another parameter to be estimated (Gelman et al, 1995). As we have more information about egg sizes, the priors were made less vague, and were set as normal distributions with mean 1.8 and variance 0.2 . The model was fitted using the WinBugs package (Spiegelhalter et al, 1999).

\section{Body size and shape}

To break variation in PC1 and PC2 down into genotypic and phenotypic components, a generalized linear mixed model (Breslow and Clayton, 1993) was employed to each component separately. The trait value was assumed to follow a normal distribution with mean $\eta_{i}$, and variance $\sigma_{\varepsilon}^{2}$ and $\eta_{i}$, was decomposed in the same way as in equation (2) above. This is the classical quantitative genetic model (Lynch and Walsh, 1998), except that the model was fitted using a Bayesian rather than a frequentist approach. Normal distributions with mean 0 and variance 100 were used as priors for the regression coefficients for the effect of egg size on the principal components. For the variance components, inverse gamma distributions with shape and scale parameters of 1 were used, as above.

To investigate whether maternal effects were mediated solely through egg size or whether they included other types of effects, we ran the analyses both with and without egg size included into the models as a covariate. Since the variance owing to egg size was always (when not in the model) captured mainly by the maternal effect term, we only present the results of models including the egg size term understanding that variance because of this term would be otherwise absorbed by the maternal effects term. The block effects are included in all models to control for small-scale temperature heterogeneity inherit to our experimental setup, and although these effects do not have any straightforward general biological interpretation outside our experimental setup, they give hints about the potential sensitivity of different traits to small variations in temperature.

In general, we assessed the significance of different effects, as well as differences between different variance component estimates, from the 2.5 and $97.5 \%$ percentiles obtained from the analyses. For ease of presentation, however, we have sometimes referred to probability values in comparisons of different effects, and they were obtained by taking the proportion of iterations in which the sample drawn from the posterior was greater (or less than) the test value.

\section{Results}

\section{Treatment effects on trait means}

Survival from fertilization until the end of the experiment was lower in low $\mathrm{pH}(70.7 \%)$ than in neutral $\mathrm{pH}$ (75.3\%), but this difference was not significant $(P=0.097$;
Figure 1a). Likewise, developmental anomalies were rare in both $\mathrm{pH}$ treatments (neutral $\mathrm{pH}$ : $2.1 \%$; low $\mathrm{pH}: 1.6 \%$ ), and their frequencies did not differ between the treatments $(P=0.087$; Figure $1 b)$. Tadpoles raised in neutral $\mathrm{pH}$ attained a significantly $\quad(5.14 \% \quad(95 \%$ $\mathrm{CI}=2.36-7.50 \%) ; P<0.001)$ larger size than their sibs raised in low $\mathrm{pH}$ (Figure 1c), but there was no difference in tadpole shape between the two treatments $(P=0.46$; Figure 1d). Hence, as evidenced by smaller size and tendency towards lower survival, tadpoles experienced the low $\mathrm{pH}$ treatment as more stressful environment than the neutral $\mathrm{pH}$ treatment.

\section{Variance component analyses}

Survival: Both the relative (Figure $2 \mathrm{a}, \mathrm{b}$ ) and absolute (Table 1) magnitudes of different causal components of variance for survival were similar in the two $\mathrm{pH}$ treatments. Maternal effects accounted for most (ca. $70 \%$ ) of the phenotypic variation in probability of survival, whereas additive and nonadditive genetic effects - which were of roughly similar magnitude in their effects - accounted for 7 and $6 \%$ of the phenotypic variation in probability of survival, respectively (Figure $1 a, b)$. Egg size had no effect on survival (Figure 2a,b), suggesting that the maternal effects on survival were not mediated through egg size effects. The block effect accounted for 11.6 and $13.4 \%$ of the variance in neutral and low $\mathrm{pH}$, respectively.

Developmental anomalies: As in the case of survival, the relative (Figure 1c,d) and absolute (Table 1)

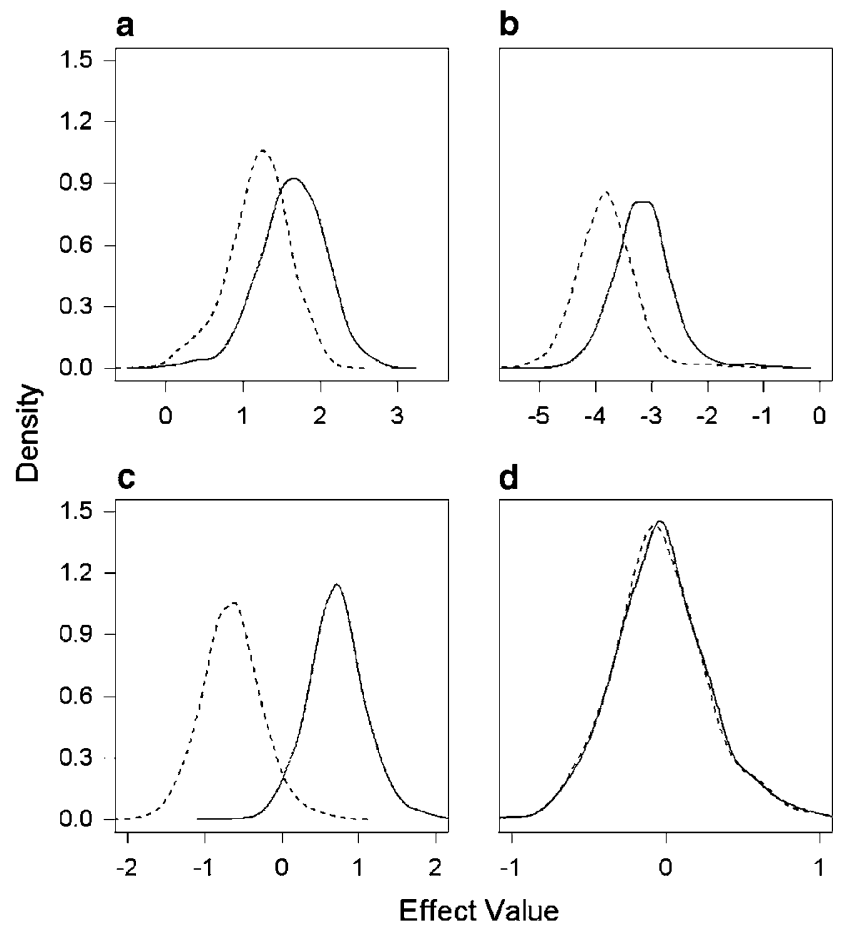

Figure 1 The effect of $\mathrm{pH}$ treatment on trait means: (a) Tadpole survival, (b) probability of being anomalous, (c) body size and (d) body shape. Graphed are posterior probability distributions from Bayesian models depicting the overall mean effect sizes (effect value; that is log odds of probabilities of survival and abnormality, and body size and shape). Solid line: neutral $\mathrm{pH}$, dashed line: low $\mathrm{pH}$. 


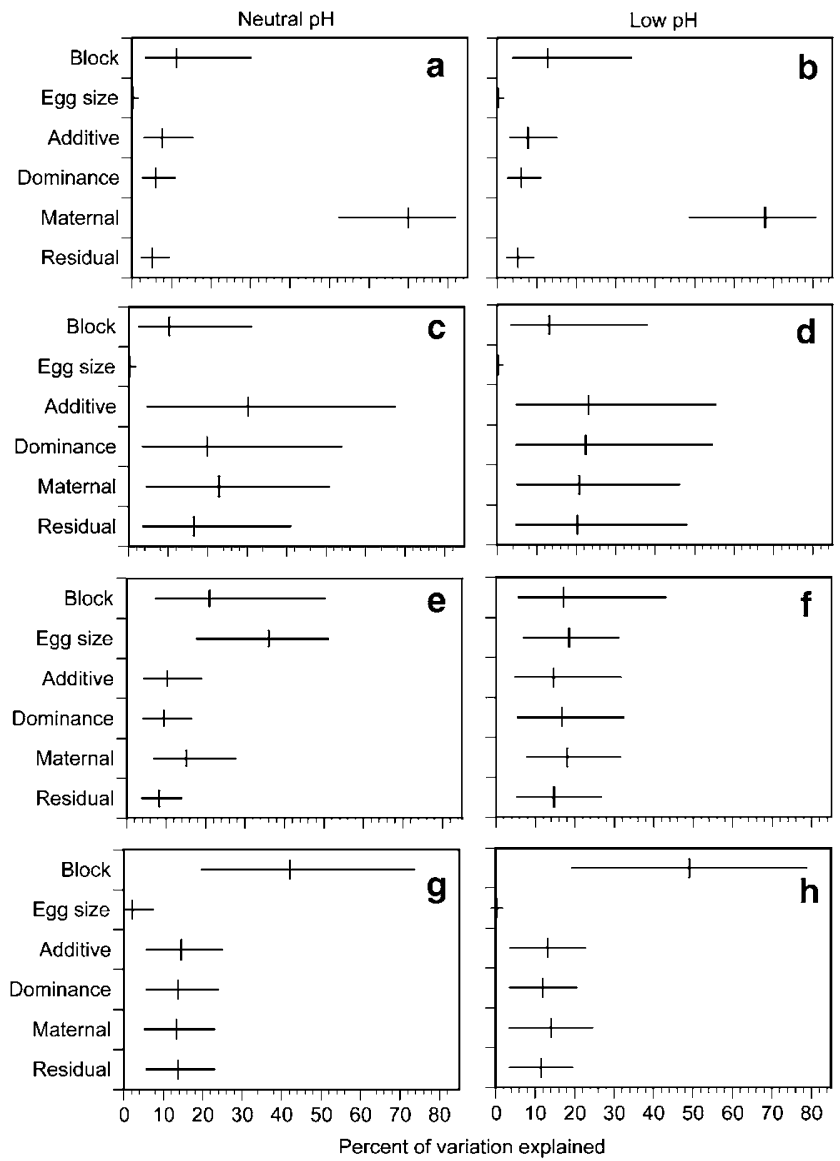

Figure 2 Relative magnitudes of different causal components of variance for different traits in two $\mathrm{pH}$ treatments. (a,b) Tadpole survival, $(\mathbf{c}, \mathbf{d})$ probability of being anomalous, $(\mathbf{e}, \mathbf{f})$ body size and (g,h) body shape. The bars indicate 2.5 and $97.5 \%$ percentiles.

magnitudes of different causal components of variance in the probability of being abnormal were roughly equal in the two $\mathrm{pH}$ treatments. Within a given treatment, maternal, additive and nonadditive effects were all significant and of approximately equal magnitude in their effects (Figure 2c,d). However, the heritabilities (posterior means: $h_{\mathrm{Neutral}}^{2}=30.2 \%$; $h_{\text {Low }}^{2}=23.1 \%$ ), and also other components of variance, were less well estimated for the probability of being abnormal than for the probability of an individual being alive because of the low numbers of abnormal individuals. Egg size had no effect on the probability of being abnormal (Figure $2 \mathrm{c}, \mathrm{d})$. The block effect accounted for 10.6 and $13.7 \%$ of the total variation in deformation occurrence in neutral and in low $\mathrm{pH}$, respectively.

Body size: Although the mean body size of tadpoles was strongly reduced by the low $\mathrm{pH}$ treatment (Figure 1c), the different causal components of variance did not differ significantly among treatments in either an absolute (Table 1) or in a relative scale (Figure 2e,f). The positive effect of egg size on body size observed under both treatments tended to be more pronounced in the neutral than in the low $\mathrm{pH}$ treatment (Table 1), but this difference was not significant $(P=0.16)$. Additive $\left(h_{\text {Neutral }}^{2}=10.2 \% ; \quad h_{\text {Low }}^{2}=14.6 \%\right)$, nonadditive and maternal effect contributions not related to egg size were of similar magnitude within and between the two treatments (Figure 2e,f). Summing up the egg sizerelated and egg size-independent maternal effects, they accounted for 51.2 and $36.8 \%$ of the variation in tadpole size in neutral and low $\mathrm{pH}$, respectively, suggesting an overwhelming role for maternal effects as determinants of body size variation.

Body shape: The variance components owing to additive $\left(h_{\text {Neutral }}^{2}=14.5 \% ; h_{\text {Low }}^{2}=13.3 \%\right)$, nonadditive and maternal effects on body shape were of roughly similar magnitude in both treatments (Table 1; Figure $2 \mathrm{~g}, \mathrm{~h})$. In contrast to body size, egg size effects were very small, but, surprisingly, almost significantly $(P=0.05)$ different in the two $\mathrm{pH}$ treatments (Table 1 ). In the neutral $\mathrm{pH}$ treatment, larger eggs produced tadpoles

Table 1 Mean values of phenotypic variance components together with 2.5 and $97.5 \%$ percentiles for tadpole survival, the occurrence of developmental anomalies, size (PC1) and shape (PC2) under different environmental conditions

\begin{tabular}{|c|c|c|c|c|c|c|c|c|}
\hline \multirow[t]{2}{*}{ Source } & \multicolumn{2}{|c|}{ Neutral } & \multicolumn{2}{|c|}{ Low } & \multicolumn{2}{|c|}{ Neutral } & \multicolumn{2}{|c|}{ Low } \\
\hline & Mean & $2.5-97.5 \%$ & Mean & $2.5-97.5 \%$ & Mean & $2.5-97.5 \%$ & Mean & $2.5-97.5 \%$ \\
\hline & Survival & & & & Anomo & & & \\
\hline Total variance & 4.399 & & 3.787 & & 6.970 & & 5.407 & \\
\hline Block & 0.509 & $0.142-1.590$ & 0.509 & $0.142-1.590$ & 0.742 & $0.185-2.490$ & 0.742 & $0.185-2.490$ \\
\hline Egg size & 0.010 & $<0.001-0.050$ & 0.009 & $<0.001-0.045$ & 0.018 & $<0.001-0.090$ & 0.015 & $<0.001-0.073$ \\
\hline Additive & 0.326 & $0.146-0.624$ & 0.284 & $0.135-0.518$ & 2.110 & $0.324-5.610$ & 1.24 & $0.260-3.390$ \\
\hline Dominance & 0.254 & $0.128-0.445$ & 0.222 & $0.114-0.384$ & 1.370 & $0.255-4.080$ & 1.20 & $0.256-3.340$ \\
\hline Maternal & 3.080 & $1.960-4.690$ & 2.570 & $1.610-3.900$ & 1.590 & $0.313-4.030$ & 1.12 & $0.267-2.920$ \\
\hline \multirow[t]{2}{*}{ Within family } & 0.220 & $0.115-0.376$ & 0.193 & $0.105-0.320$ & 1.140 & $0.256-3.130$ & 1.09 & $0.260-2.870$ \\
\hline & Size & & & & Shape & & & \\
\hline Total variance & 3.040 & & 3.740 & & 1.080 & & 0.931 & \\
\hline Block & 0.698 & $0.191-2.260$ & 0.698 & $0.191-2.260$ & 0.510 & $0.143-1.590$ & 0.507 & $0.143-1.590$ \\
\hline Egg size & 1.080 & $0.536-1.640$ & 0.689 & $0.260-1.290$ & 0.023 & $<0.001-0.073$ & 0.003 & $<0.001-0.013$ \\
\hline Additive & 0.300 & $0.140-0.532$ & 0.539 & $0.190-1.150$ & 0.144 & $0.085-0.222$ & 0.109 & $0.070-0.160$ \\
\hline Dominance & 0.276 & $0.139-0.450$ & 0.612 & $0.221-1.120$ & 0.137 & $0.084-0.204$ & 0.100 & $0.066-0.140$ \\
\hline Maternal & 0.444 & $0.230-0.769$ & 0.671 & $0.299-1.210$ & 0.134 & $0.078-0.219$ & 0.117 & $0.071-0.187$ \\
\hline Within family & 0.242 & $0.131-0.376$ & 0.535 & $0.213-0.920$ & 0.137 & $0.089-0.191$ & 0.095 & $0.065-0.130$ \\
\hline
\end{tabular}


with relatively long tails, but this was not the case in low $\mathrm{pH}$ treatment (Table 1). Block effects on body shape were large (Figure $2 \mathrm{~g}, \mathrm{~h}$ ), suggesting that small variations in developmental temperature had a large effect in determining tadpole body proportions.

\section{Discussion}

The most salient features of our results were that all traits - including viability itself - were significantly heritable under the environmental conditions tested, and that the relative magnitudes of additive and nonadditive genetic contributions to variability in a given trait were typically about equal. In general, there was very little evidence for drastic environment dependency in the expression of genetic variability in any of the traits, but there was some evidence for the environment dependency of maternal effects. In what follows, we will discuss the implications of each of these findings in turn, and, in particular, in the context of the current debate on the heritability of different types of traits under different environmental conditions.

A general picture emerging from studies of wild animal populations is that the closer association a trait has with fitness, the lower its heritability is likely to be (Mousseau and Roff, 1987; Houle, 1992; Merilä and Sheldon, 1999, 2000; Kruuk et al, 2000; Stirling et al, 2002). The results of the present study conform to this general pattern: all four fitness-associated traits were significantly heritable, but the heritabilities were low. However, as in the case of most earlier studies - barring few exceptions (eg Kruuk et al, 2000; Merilä and Sheldon, 2000) - we have no objective way of ordering the different traits according to their impact on fitness. Clearly, viability itself must be a very strong correlate of fitness, and the same is probably true in the case of the probability of being abnormal: survival of deformed tadpoles in this species is known to be very low (Beattie et al, 1992), which is also suggested by our finding that there was a positive correlation between the posterior probability of a tadpole being alive, and its being abnormal. Also, tadpole body size is likely to be an important component of fitness as it is positively correlated with size at metamorphosis (Kaplan, 1992; Semlitsch and Schmiedehausen, 1994), which in turn correlates positively with further survival probability (Altwegg and Reyer, 2003 and references therein), size at maturity (Smith, 1987) and fecundity (Smith, 1987; Semlitsch et al, 1988). The relation between body shape and fitness is less clear, but we note that body shape differences are an important component of antipredator defences in frog tadpoles (Lardner, 2000; Relyea, 2001), and predation is one of the most important sources of mortality in larval amphibians (Newman, 1992). Whatever the relative importance of these traits in their contribution to fitness, our results show that they exhibit heritabilities typical of fitness traits.

An interesting feature of our results was that the size of the dominance genetic component in all traits was approximately of the same size as the additive genetic component in the same trait. There is a fairly large amount of nonadditive genetic variation corresponding to an average coefficient of dominance variance $\left(\mathrm{CV}_{\mathrm{D}}=V_{\mathrm{D}} /\left(V_{\mathrm{A}}+V_{\mathrm{D}}\right)\right.$; Crnokrak and Roff, 1995) of ca. 0.47 (range $=0.39-0.53$ ). Although the data are still scanty, Crnokrak and Roff (1995) found that dominance genetic contributions to fitness traits were larger for traits closely associated with fitness than those less closely associated with fitness. Such a pattern is to be expected under the scenario where directional selection erodes additive genetic variance from traits closely related to fitness, thereby increasing the relative proportion of nonadditive variance to the total genetic variance (Merilä and Sheldon, 1999). The high dominance contributions observed in this study are fully consistent with this reasoning, and hint also about relatively high load of recessive harmful/deleterious mutations segregating in our study population. This genetic load is a potential source of inbreeding depression for which evidence from wild populations has been accumulating rapidly during the past decades (Crnokrak and Roff, 1999; Hedrick and Kalinowski, 2000; Keller and Waller, 2002). However, as our breeding design does not allow dominance variance to be estimated independently of other causal components of variance (cf. equation (3)), some caution is needed in interpretation. Nevertheless, as the size of the dominance contributions were fairly similar in both $\mathrm{pH}$ treatments, our results do not suggest that the effects of inbreeding depression for the traits studied would differ depending on the $\mathrm{pH}$ to which developing tadpoles are exposed.

Although there is evidence that stress-dependent changes in the expression of genetic variability are common (Hoffmann and Merilä, 1999; Hoffmann and Hercus, 2000), we found little evidence for stressdependent changes in heritability estimates or underlying causal components of variance. It is unlikely that the environmental stress in our experiment was insufficient: tadpole size was significantly reduced in the low $\mathrm{pH}$ treatment as compared to neutral $\mathrm{pH}$ treatment, which suggests that tadpoles did experience the low $\mathrm{pH}$ treatment as stressful. Hence, varying amounts of environmental stress did not seem to influence the expression of genetic variability in the traits studied. This is consistent with the results of other recent studies that have failed to detect stress-dependent differences in the expression of additive genetic variation (Bubliy et al, $2000,2001)$. However, it is worth pointing out that our results cannot be generalized to other types of environmental stresses: although different types of stresses can cause the same kind of changes in phenotypic variation (Imasheva et al, 1998, 1999), responses to different types of stressors are not necessarily genetically correlated (Dahlgaard and Hoffmann, 2000).

Apart from the small and significant genetic effects, a feature central to our results is the pervasive role of maternal effects as determinants of variation in all traits. In the case of tadpole survival, maternal effects were the most important source of variation accounting for $70 \%$ of the variance in the probability of survival. Maternal effects were also important for the probability of being abnormal, but here their estimated effects were of the same magnitude as the genetic effects. In the case of both of these traits, the maternal effects were largely independent of egg size effects, suggesting that viability and developmental stability are not strongly linked to egg size effects per se. In contrast, the maternal effects acting on body size and shape were more strongly mediated through egg size effects, and in both cases indications of environmental dependency were obtained. The positive effect of egg size on tadpole size tended to be more 
pronounced at neutral $\mathrm{pH}$ than at low $\mathrm{pH}$. Evidence for similar environment-dependent expression of maternal/ parental effects is also available for other amphibians (Kaplan, 1992; Parichy and Kaplan, 1992) and a wide range of other taxa (eg Einum and Fleming, 1999). Hence, maternal effects are a possible means if improving the fitness of common frog offspring being subjected to acid stress.

In contrast to tadpole size, tadpole shape was not affected by $\mathrm{pH}$ treatment. This does not mean that tadpole shape would be more canalised than tadpole size, as the tadpole shape was strongly affected by the block effect, suggesting that small differences in temperature had large effects on tadpole shape. In fact, correlating the mean tadpole shape per block against the block-specific average temperature revealed a tendency for a positive correlation $(r=0.64, n=5, P=0.087)$ between tadpole shape and temperature. This is a wellknown phenomenon from amphibians: tadpoles grown under cooler temperatures tend to grow longer tails than those grown under warmer temperatures (Kaplan, 1992).

In conclusion, the results of this study give little evidence to support the conjecture that environmental stress created by low $\mathrm{pH}$ would impact strongly on the genetic architecture of fitness-related traits in frogs, and thereby hamper adaptation to stress caused by acidification. On the contrary, our analyses suggest that viability and viability-related traits are heritable under a wide range of $\mathrm{pH}$ values, although the heritability of these traits is low, and quite easily over-ridden in importance by maternal and/or environmental effects. The low heritabilities and high dominance contributions in all traits conform to the pattern typical of fitness traits, and suggest that these traits are subject to relatively strong directional selection and inbreeding depression.

\section{Acknowledgements}

We thank Paavo Junttila, Katja Räsänen, Anssi Laurila, and Indrek Ots for their invaluable help in the practical implementation of the experiment. Our research was supported by the Swedish Natural Sciences Research Council (JM), the Swedish Agriculture and Forestry Research Council (JM), NorFA (SP, JM), and the Academy of Finland (JM, SP). This study was performed with the permission of the Ethical Committee of Uppsala University.

\section{References}

Alford RA, Richards SJ (1999). Global amphibian declines: a problem in applied ecology. Annu Rev Ecol Syst 30: 133-165.

Altwegg R, Reyer U-H (2003). Patterns of natural selection on size at metamorphosis in water frogs. Evolution, in press.

AMAP (1998). Acidifying Pollutants, Arctic Haze and Acidification in the Arctic. Assessment Report. Arctic pollution issues. Arctic Monitoring and Assessment Programme (AMAP): Oslo. pp 621-659.

Andrén C, Henrikson L, Olsson M, Nilson G (1988). Effects of $\mathrm{pH}$ and aluminium on embryonic and early larval stages of Swedish brown frogs Rana arvalis, $R$. temporaria and $R$. dalmatina. Hol Ecol 11: 127-135.

APHA (1985). Standard Methods for the Examination of Water and Wastewater, 16th edn. American Public Health Association: Washington.
Arnold SJ, Pfrefender ME, Jones AG (2001). The adaptive landscapes as conceptual bridge between micro- and macroevolution. Genetica 112-113: 9-32.

Aston RJ, Beattie RC, Milner AGP (1987). Characteristics of spawning sites of the common frog (Rana temporaria) with particular reference to acidity. J Zool 213: 233-242.

Beattie RC, Tyler-Jones R, Baxter MJ (1992). The effects of $\mathrm{pH}$, aluminium concentration and temperature on the embryonic development of the European common frog, Rana temporaria. J Zool 228: 557-570.

Bijlsma R, Loeschke V (eds) (1997). Environmental Stress, Adaptation and Evolution. Birkhäuser Verlag: Basel.

Blaustein AR, Kiesecker JM, Chivers DP, Hokit DG, Marco A, Belden Lk et al (1998). Effects of ultraviolet radiation on amphibians: field experiments. Am Zool 38: 799-812.

Breslow NE, Clayton DG (1993). Approximate inference in generalized linear mixed models. J Am Statist Ass 88: 9-25.

Bridges CM, Semlitsch RD (2000). Variation in pesticide tolerance of tadpoles among and within species of Ranidae and patterns of amphibian decline. Cons Biol 14: 1490-1499.

Bubliy OA, Loeschcke V, Imasheva AG (2000). Effect of stressful and nonstressful growth temperatures on variation of sternopleural bristle number in Drosophila melanogaster. Evolution 54: 1444-1449.

Bubliy OA, Loeschcke V, Imasheva AG (2001). Genetic variation of morphological traits in Drosophila melanogaster under poor nutrition: isofemale lines and offspring-parent regression. Heredity 86: 363-369.

Bürger R, Lynch M (1997). Adaptation and extinction in changing environments. In: Bijlsma $\mathrm{R}$, Loeschke $\mathrm{V}$ (eds) Environmental Stress, Adaptation and Evolution, Birkhäuser Verlag: Heidelberg. pp 209-240.

Böhmer J, Rahman H (1990). Influence of surface water acidification on amphibians. In: Hanke W (ed) Biology and Physiology of Amphibians, Gustav Fisher Verlag: Stuttgart. pp 287-309.

Corn PS (2000). Amphibian declines: review of some current hypotheses. In: Sparling DW, Bishop CA, Linder G (eds) Ecotoxicology of Amphibians and Reptiles. Society of Environmental Toxicology and Chemistry: Pensacola, FL. pp 663696.

Crnokrak P, Roff DA (1995). Dominance variance: associations with selection and fitness. Heredity 75: 530-540.

Crnokrak P, Roff DA (1999). Inbreeding depression in the wild. Heredity 83: 260-270.

Cummins CP (1986). Effects of aluminium and low $\mathrm{pH}$ on growth and development in Rana temporaria tadpoles. Oecologia 69: 248-252.

Dahlgaard J, Hoffmann AA (2000). Stress resistance and environmental dependency of inbreeding depression in Drosophila melanogaster. Cons Biol 14: 1187-1192.

Einum S, Fleming IA (1999). Maternal effects of egg size in brown trout (Salmo trutta): Norms of reaction to environmental quality. Proc $R$ Soc Lond B 266: 2095-2100.

Forbes, V (1999). Genetics and Ecotoxicology. Taylor \& Francis: Washington, DC.

Gelman A, Carlin J, Rubin D (1995). Bayesian Data Analysis. Chapman \& Hall: London.

Gosner KL (1960). A simplified table for staging anuran embryos and larvae with notes on identification. Herpetologica 16: 183-190.

Groeters FR, Dingle H (1987). Genetic and maternal influences on life history plasticity in response to photoperiod by milkweed bugs (Oncopeltus fasciatus). Am Nat 129: 332-346.

Hedrick PW, Kalinowski ST (2000). Inbreeding depression in conservation biology. Annu Rev Ecol Syst 31: 139-162.

Hecnar SJ (1995). Acute and chronic toxicity of ammonium nitrate fertilizer to amphibians from southern Ontario. Environ Tox Chem 14: 2131-2137.

Hoffmann AA, Hercus MJ (2002). Environmental stress as an evolutionary force. BioScience 50: 217-226. 
Hoffmann AA, Merilä J (1999). Heritable variation and evolution under favourable and unfavourable conditions. Trends Ecol Evol 14: 96-101.

Hoffmann AA, Parsons PA (1997). Extreme Environmental Change and Evolution. Cambridge University Press: Cambridge.

Houlahan JE, Findley CS, Schmidt BR, Meyer AH, Kuzmin SL (2000). Quantitative evidence for global amphibian population declines. Nature 404: 752-755.

Houle D (1992). Comparing evolvability and variability of quantitative traits. Genetics 130: 195-204.

Imasheva AG, Bosenko DV, Bubliy OA (1999). Variation in morphological traits of Drosophila melanogaster (fruit fly) under nutritional stress. Heredity 82: 187-192.

Imasheva AG, Loeschcke V, Zhivotovsky LA, Lazebny OE (1998). Stress temperatures and quantitative variation in Drosophila melanogaster. Heredity 81: 246-253.

Kaplan RH (1992). Greater maternal investment can decrease offspring survival in the frog Bombina orientalis. Ecology 73: 280-288.

Kaplan RH (1998). Maternal effects, developmental plasticity, and life history evolution: an amphibian model. In: Mousseau TA, Fox CW (eds) Maternal Effects as Adaptations, Oxford University Press: New York. pp 244-260.

Kruuk LEB, Clutton-Brock TH, Slate J, Pemberton JM, Brotherstone S, Guinnes FE (2000). Heritability of fitness in a wild mammal population. Proc Natl Acad Sci USA 97: 698-703.

Kearsey M, Pooni M (1996). Genetical Analysis of Quantitative Traits. Chapman \& Hall: London.

Keller LF, Waller DM (2002). Inbreeding effects in wild populations. Trends Ecol Evol 17: 230-241.

Lardner B (2000). Morphological and life history responses to predators in larvae of seven anurans. Oikos 88: 169-180.

Lynch M, Lande R (1993). Evolution and extinction in response to environmental change. In: Kareiva P, Kingsolver JG, Huey RB (eds) Biotic Interactions and Global Change, Sinauer: Sunderland. pp 234-250.

Lynch M, Walsh B (1998). Genetics and Analysis of Quantitative Traits. Sinauer Ass., Inc. Sunderland, MK.

McCullagh P, Nelder JA (1989). Generalized Linear Models. Chapman \& Hall: London.

Merilä J (1997). Expression of genetic variation in body size of the collared flycatcher under different environmental conditions. Evolution 51: 526-536.

Merilä J, Fry JD (1998). Genetic variation and causes of genotype-environment interaction in the body size of blue tit (Parus caeruleus). Genetics 148: 1233-1244.

Merilä J, Sheldon BC (1999). Genetic architecture of fitness and nonfitness traits: empirical patterns and development of ideas. Heredity 83: 103-109.

Merilä J, Sheldon BC (2000). Lifetime reproductive success and heritability in nature. Am Nat 155: 301-310.
Mousseau TA, Fox CW (eds) (1998). Maternal Effects as Adaptations. Oxford University Press: New York.

Mousseau TA, Roff DA (1987). Natural selection and the heritability of fitness components. Heredity 59: 181-197.

Newman RA (1992). Adaptive plasticity in amphibian metamorphosis. BioScience 42: 671-678.

Parichy DM, Kaplan RH (1992). Maternal effects on offspring growth and development depend on environmental quality in the frog Bombina orientalis. Oecologia 91: 579-586.

Räsänen K, Laurila A, Merilä J (2002). Carry-over effects of embryonic acid conditions on development and growth of Rana temporaria tadpoles. Freshwater Biol 47: 19-30.

Reader JP, Dempsey CH (1989). Episodic changes in water quality and their effects on fish. In: Morris R, Taylor EW, Brown DJ, Brown JA (eds) Acid Toxicity and Aquatic Animals, Cambridge University Press: Cambridge. pp 67-83.

Relyea RA (2001). Morphological and behavioral plasticity of larval anurans in response to different predators. Ecology 82: 523-540.

Riska B, Prout T, Turelli M (1989). Laboratory estimates of heritability and genetic correlations in nature. Genetics 123: 865-871.

Rosenshield ML, Jofre MB, Karasov WH (1999). Effects of polychlorinated biphenyl 126 on green frog (Rana clamitans) and leopard frog (Rana pipiens) hatching success, development, and metamorphosis. Env Tox Chem 18: 2478-2486.

Rugh R (1962). Experimental Embryology. Burgess Publishing Company: Minneapolis, MN.

Semlitsch RD, Schmiedehausen S (1994). Paternal contribution to variation in hatchling size and its relationship to growth and metamorphosis in tadpoles of Rana lessonae and Rana esculenta. Copeia 1994: 406-412.

Semlitsch RD, Scott DE, Pechmannn JHK (1988). Time and size at metamorphosis related to adult fitness in Ambystoma talpoideum. Ecology 71: 1789-1795.

Sgró CM, Hoffmann AA (1998). Effects of stress combinations on the expression of additive genetic variation for fecundity in Drosophila melanogaster. Genet Res 72: 13-18.

Smith DC (1987). Adult recruitment in chorus frogs: effects of size and date at metamorphosis. Ecology 68: 344-350.

Spiegelhalter DJ, Thomas A, Best NG (1999). WinBUGS Version 1.2 User Manual. MRC Biostatistics Unit, Cambridge, UK.

Stirling DG, Reale D, Roff DA (2002). Selection, structure and the heritability of behaviour. J Evol Biol 15: 277-289.

Tyler-Jones R, Beattie RC, Aston RJ (1989). The effects of acid water and aluminium on the embryonic development of the common frog, Rana temporaria. J Zool 219: 355-372.

Walther GR, Post E, Convey P, Menzel A, Parmesan C, Beebee TJC et al (2002). Ecological responses to recent climate change. Nature 416: 389-395. 